\title{
Geospatial Distribution of Public Secondary in Gombe Local Government Area, Gombe State of Nigeria
}

\author{
Yila Caiaphas Makadi, Rabecca Stephen Sati, Ismail Dankaka
}

Gombe State University, Faculty of Science Department of Geography P.M.B 127, Gombe, Gombe State, Nigeria

E-mail: ycaiaphas@gmail.com

\begin{abstract}
The paper reviews research tradition of accessibility level and spatial distribution of student in public secondary school in gombe local government area, Gombe state. Primary and secondary data were used for the study. Primary data was collected using questionnaire and a hand-held GPS receiver to capture the coordinate points of schools and other relevant data. Secondary data include administrative map, population figures of both students and Teachers, Names and addresses of the secondary schools in the study area. The data were analyzed using geographic information techniques. From the data survey carried out, the result of the analysis showed the accessibility level and spatial distribution of school in Gombe were seventeen (17) public senior secondary and total number of students were nineteen thousand and eleven $(19,011)$. The nearest neighbor analysis (NNA) for the spatial pattern of school were carried out based on each ward in study area which as ten (10) wards in each ward revealed two major spatial distributions. The spatial pattern of the Gombe LGA has Nearest Neighbour Ratio (NNR): 3.385087, Bolari East ward with NNR: 3.385087 and Shamaki wards NNR: 1.600148, which showed dispersed pattern, while Jekada Fari ward with NNR: 0.214890, Pantami ward with NNR: 0.226863, and Herwo Gana wards with NNR: 0.185239, were showed clustered pattern. The nearest neighbor index shows clustered pattern for all the wards in the local government area except Bolari East and Shamaki wards that has dispersed pattern of distribution. The implication of these two patterns means that accessibility is poor in the study area. Students travel than normal to overcome the function of distance.
\end{abstract}

Keywords: Accessibility; Spatial distribution; Nearest neighbor analysi; Secondary school; GIS.

\section{INTRODUCTION}

Accessibility is defined as the distance to which people must travel to receive services, or from which a service is provided to the whole community of interest in administration, economy, education, health etc. (Lineberry, 2000). It is believed that accessibility is a concept that has taken on a variety of meaning, including the amount of effort required by a person to reach a destination or the number of activities which can be reached from a certain location (Geurs and Ritsema 2001). The concept of accessibility is used in many contexts and in different ways, for example, as a goal in transportation policy, as a means in rural development policy, as an indicator of rural deprivation and as a variable in location analysis (Lu, 2004). "Education plays an important role in our society. United Nations Educational, Scientific, and cultural Organization indicate that the development of education is important to the development of economy all over the world". World Bank points out that the Gross Domestic Product (GDP) of a country will increase 3\% every year with increasing level of education (World Bank1996). Education system is a complex organization of interactions between interdependent bodies, groups and individuals, all aimed at the achievement of educational goals. The stakeholders are usually the governments and religious groups, voluntary organizations, Teachers' Associations, the teachers, the parents and the public (Ijaduola, 1998). Secondary education spreads over the ages of 10 years and 13 years for junior secondary schools, and then 14 years to 16 years for the senior secondary Schools. These 
are the years of adolescence. These are the years of transition; indeed, most crucial years of life. There are steady and fast changes in the body structure transforming to adult form and image of life. At this age, the bodily changes take final shape and stabilize. This is also the stage of emotional transformation and maturity that swings between joy and trauma (Ogunyemi,2014). The use of GIS based will play are vital roles in measuring level whereas accessible pattern of spatial distribution of schools. However, high resolution image, coordinate and questionnaire data of Gombe were using for the analysis.

Aim of the research is to examine geospatial distribution of public secondary schools in Gombe Local Government Area, of Gombe state thought the following objectives: a) to determine/ascertain the spatial location of public secondary schools in Gombe local government area; and b) to examine the spatial distribution pattern of secondary schools in Gombe local government.

\section{METHOD}

Primary and secondary data were used for this work; these includes: questionnaire, hand-held GPS receiver, administrative map of Gombe local government area wards, high resolution Google Earth image 2017, and Nigeria shape file.

The GPS receiver was used to capture the geographic coordinate points of schools, Secondary data include administrative map, population figures of both students and teachers, names and addresses of the secondary schools in the study area. The administrative map was scanned and geo referenced to WGS 1984 UTM Zone 32N.Personal geo database, feature dataset and feature classes for existing settlements, roads and wards were created in GIS environment. The existing roads, settlements and wards were therefore digitized from the georeferenced administrative map using the above stated feature classes. The data obtained from the administered questionnaire, School data and GPS point coordinates of secondary schools were collected, typed into excel spread sheet and saved as .csv format for easy import into GIS environment.

\section{Study area}

Gombe LGA is located in Gombe State lies between Longitudes $11^{\circ} 14^{\prime} 07^{\prime \prime} \mathrm{E}$ and $11^{\circ} 4^{\prime} 42^{\prime \prime} \mathrm{E}$, and Latitudes $10^{\circ} 16^{\prime} 48^{\prime \prime} \mathrm{N}$ and $10^{\circ} 17^{\prime} 24^{\prime \prime} \mathrm{N}$. The area is bounded on the East by Yamatul Deba local Government and on the West by Akko Local Government and north by Kwami. The study area is inhabited predominantly by the Hausa/Fulani speaking language. With ten (10) wards (Ajiya, Bajoga, Bolari, Bolari east, Dawaki, Herwa Gana, Jekada Fari, Nasarawo, Pantami and Shamaki). And seventeen (17) public secondary school with total number of nineteen thousand and eleven $(19,011)$ student. It has a total land area of 120 square kilometers, with population of 268,000 (NPC, 2006) and 2016 projected population 367,000 inhabitants (NPC, 2016). 


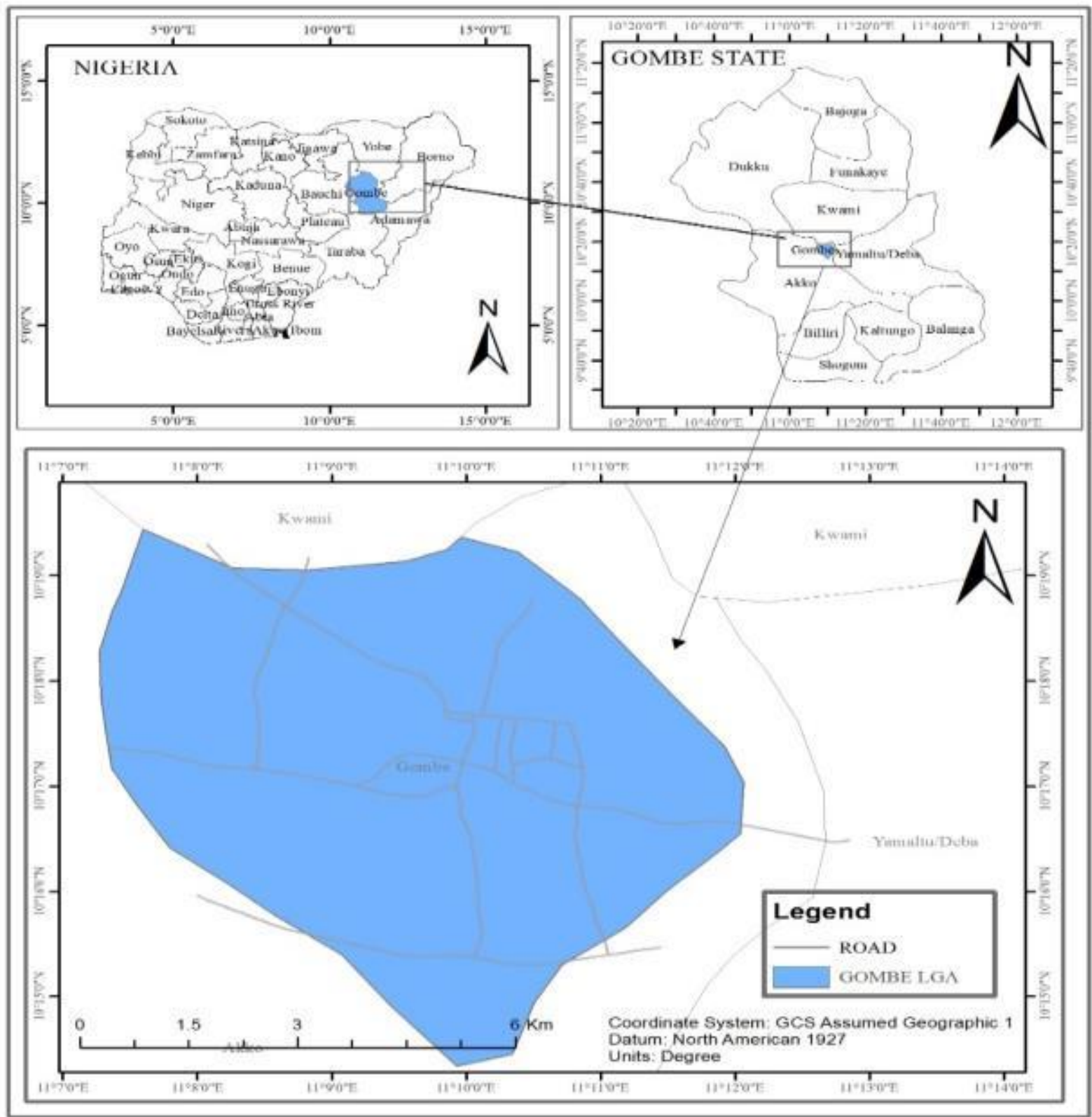

Fig :1 Study area

\section{RESULT AND DISCUSSION}

\section{0: Mapping of the public secondary schools and their coordinate location in Gombe LGA}

The field survey and data collected reveal that there are 17 public secondary schools in Gombe local government area. 


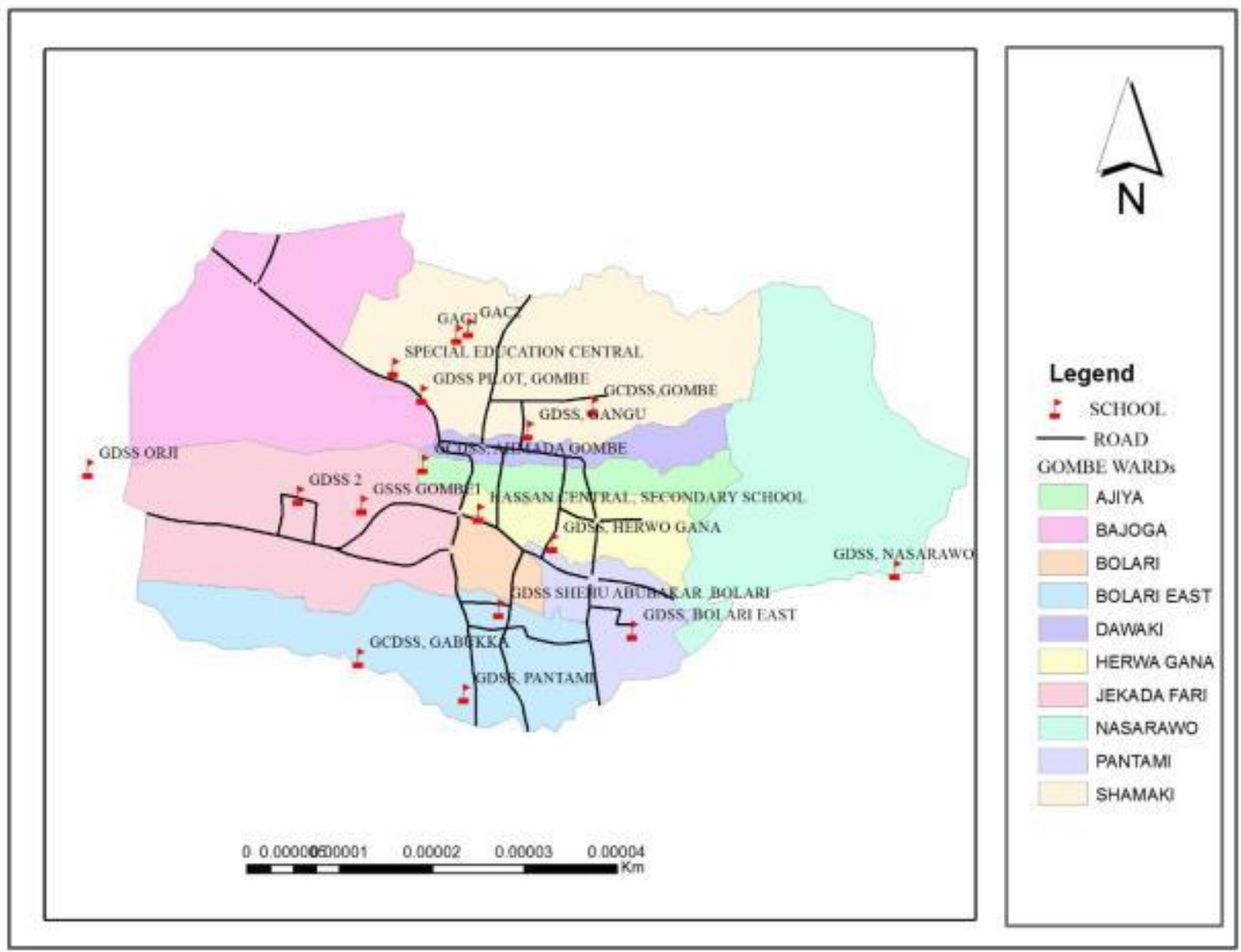

Fig:2 the location of public secondary school in study area

Table 1: Secondary schools in Gombe local government area with their coordinates.

\begin{tabular}{llll}
\hline S/N & NAME OF SECONDARY SCHOOLS & \multicolumn{2}{c}{ EASTING } \\
& NORTHING & 11.16 & 10.30 \\
\hline 1. & Government arabia college 2 & 11.16 & 10.36 \\
\hline 2. & Government arabia college 1 & 11.16 & 10.29 \\
\hline 3. & Government day comprehensive college senior sch & 11.18 & 10.30 \\
\hline 4. & Government day senior school, gombe & 11.18 & 10.27 \\
\hline 5. & Government day senior school, bolari east & 11.17 & 10.29 \\
\hline 6. & Government day senior school, gangu & 11.17 & 10.28 \\
\hline 7. & Government day senior school, herwo gana & 11.21 & 10.28 \\
\hline 8. & Government day senior school, nasarawo & 11.12 & 10.29 \\
\hline 9. & Government day senior school orji & 11.16 & 10.27 \\
\hline 10. & Government day senior school, pantami & 11.16 & 10.30 \\
\hline 11. & Government day senior school pilot, gombe & 11.17 & 10.27 \\
\hline 12. & Government day senior school shehu, bolari & &
\end{tabular}




\begin{tabular}{clll}
\hline 13. & Government day senior school, gabukka & 11.15 & 10.27 \\
\hline 14. & Government senior science school, gombe1 & 11.16 & 10.29 \\
\hline 15. & Government day science school 2 & 11.14 & 10.30 \\
\hline 16. & Hassan central, gombe & 11.16 & 10.29 \\
\hline 17. & Special education central & 11.15 & 10.30 \\
\hline
\end{tabular}

Source: field work

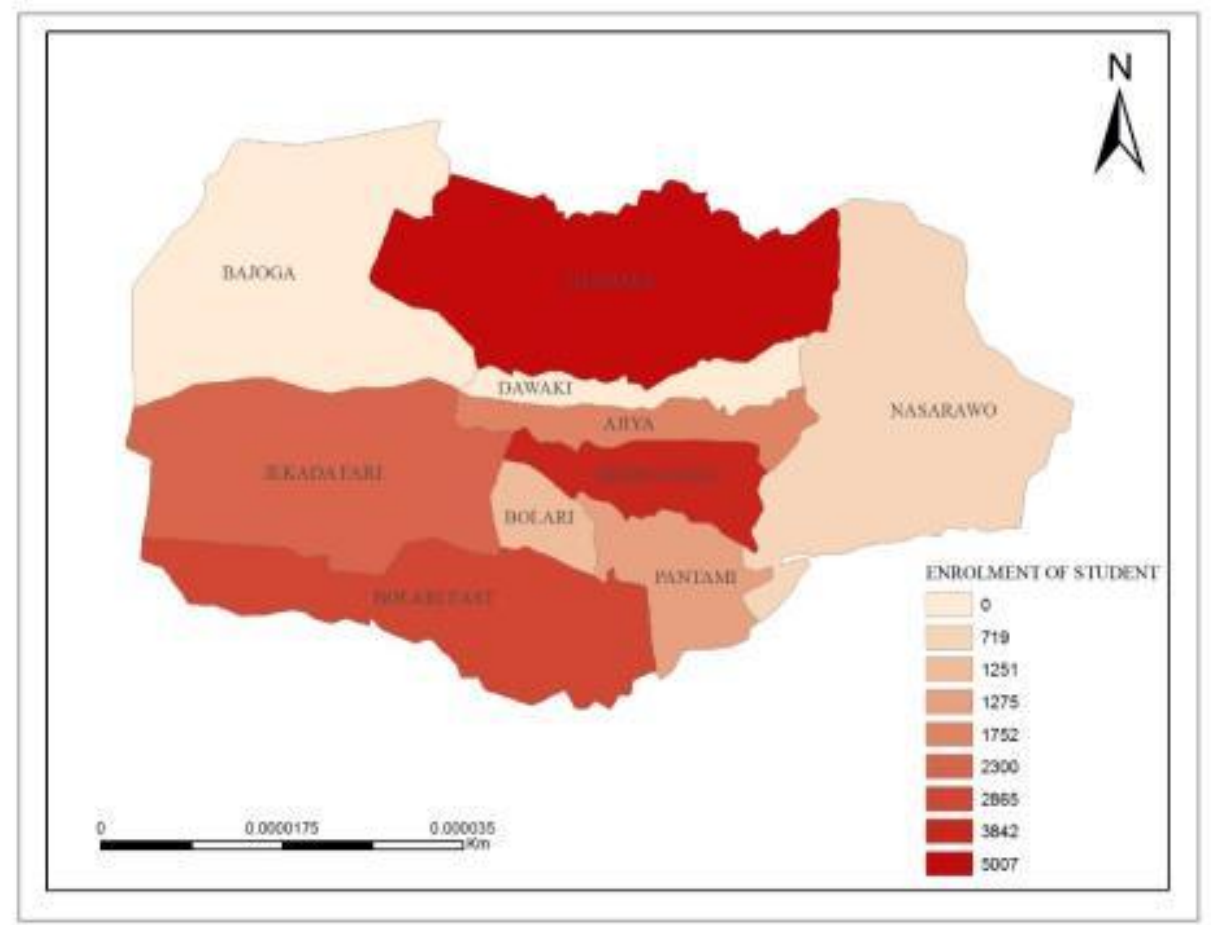

Fig:3 Enrolment of student in Gombe Local Government based on Ward Distribution

Table 2: ADDRESSES OF SECONDARY SCHOOLS WITH TOTAL ENROLMENT IN GOMBE LGA S/N NAME OF SECONDARY SCHLS TOTAL

\section{ENROLMENT}

1. GAC2

2. GAC1

3. GDCSS, AHMADA GOMBE

4. GCDSS, GOMBE

5. GDSS, BOLARI EAST

6. GDSS, GANGU

7. GDSS, HERWO GANA

8. GDSS, NASARAWO

9. GDSS ORJI

10. GDSS, PANTAMI

11. GDSS PILOT, GOMBE 
13. GCDSS, GABUKKA

14. GSSS, GOMBE1

15. GDSS 2

16. HASSAN CENTRAL, GOMBE

17. SPECIAL EDUCATION CENTRAL

Total number of the student
770

871

621

117

\section{Nearest neighbor analysis of the schools in the study area.}

\section{Spatial Accessibility Index}

Nearest Neighbour analysis (NNA) was used to determine the pattern of secondary schools in each ward. Total number of each school in the ward (which represent $n$ ), the size of the area (which represent a) and Manhattan distance was used to determine the pattern of secondary schools in each ward and Rn value, $\mathrm{Z}$ score, Observed mean distance/ Expected mean Distance and $\mathrm{p}$ - value were generated.

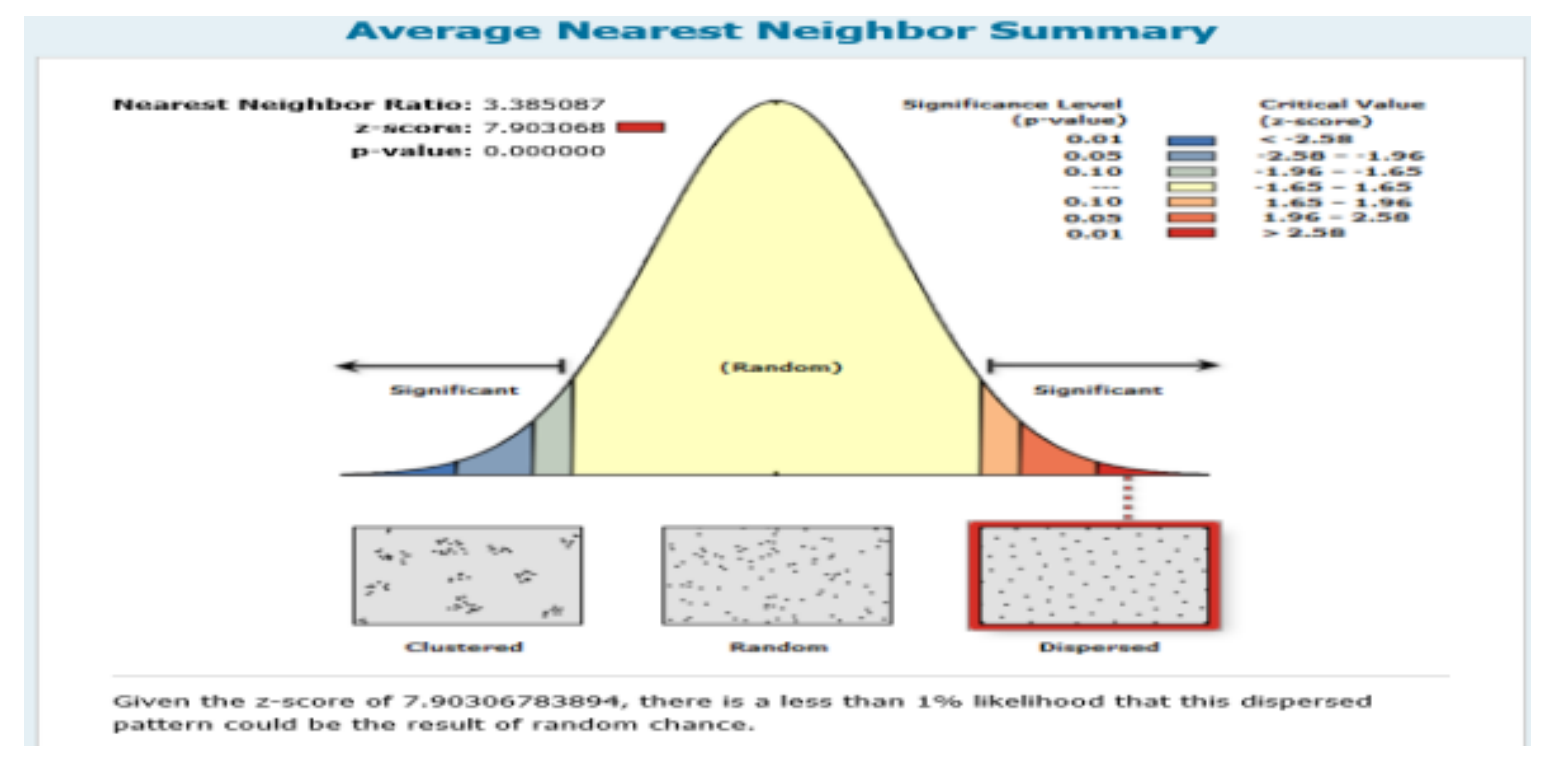

Figure 4: Analysis for Public Secondary Schools in Gombe Local Government Area

The Nearest Neighbour Analysis of Gombe L.G.A here revealed an $\mathrm{Rn}=0.01$ and critical value of $>2.58$, with $\mathrm{N}=17$, study area $=52 \mathrm{~km}^{2}$, Nearest Neighbour Ratio: 3.385087 , observed mean distance $=0.0106$, Expected mean Distance $=0.0031$, and the test significance: $\mathrm{p}-$ value $0.000000 \mathrm{z}=$ 7.903068. The result of the analysis showed that all the schools are dispersed and there is no even distribution of schools in the area. 


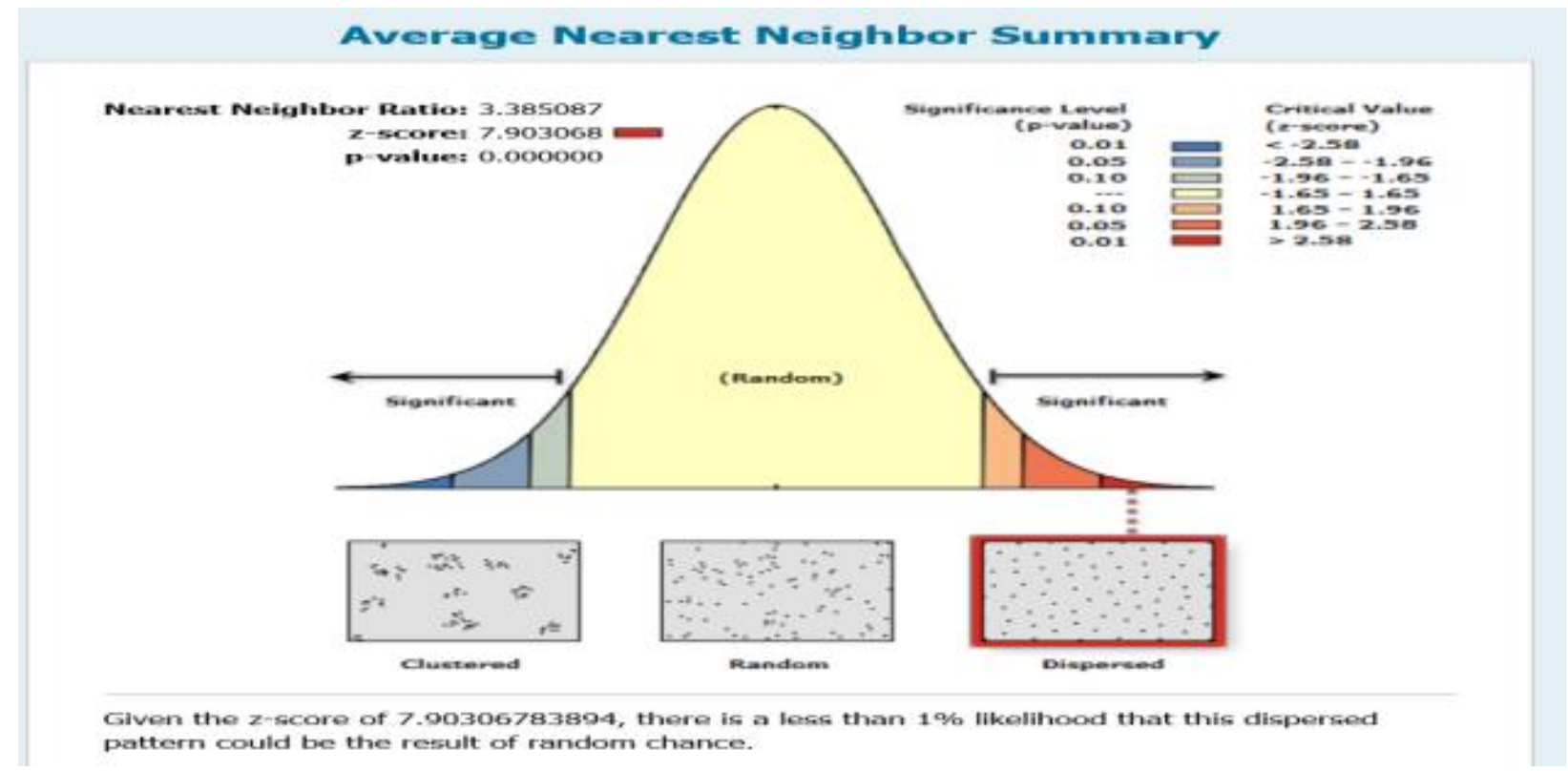

Figure 5: Analysis for Public Secondary Schools in Bolari East

The Nearest Neighbour Analysis of Bolari east ward here revealed that $\mathrm{Rn}=0.01$ and critical value of $>2.58$, with $\mathrm{N}=3$, ward area $=13.7 \mathrm{~km}^{2}$, Nearest Neighbour Ratio: 3.385087 , observed mean distance= 0.0106, Expected mean Distance $=0.0031$, and the test significance: $\mathrm{p}-$ value $0.000000 \mathrm{z}$ - score $=$ 7.903068. The result of the analysis showed that all the schools are dispersed and there is no even accessibility to secondary schools in the area.

\section{Average Nearest Neighbor Summary}

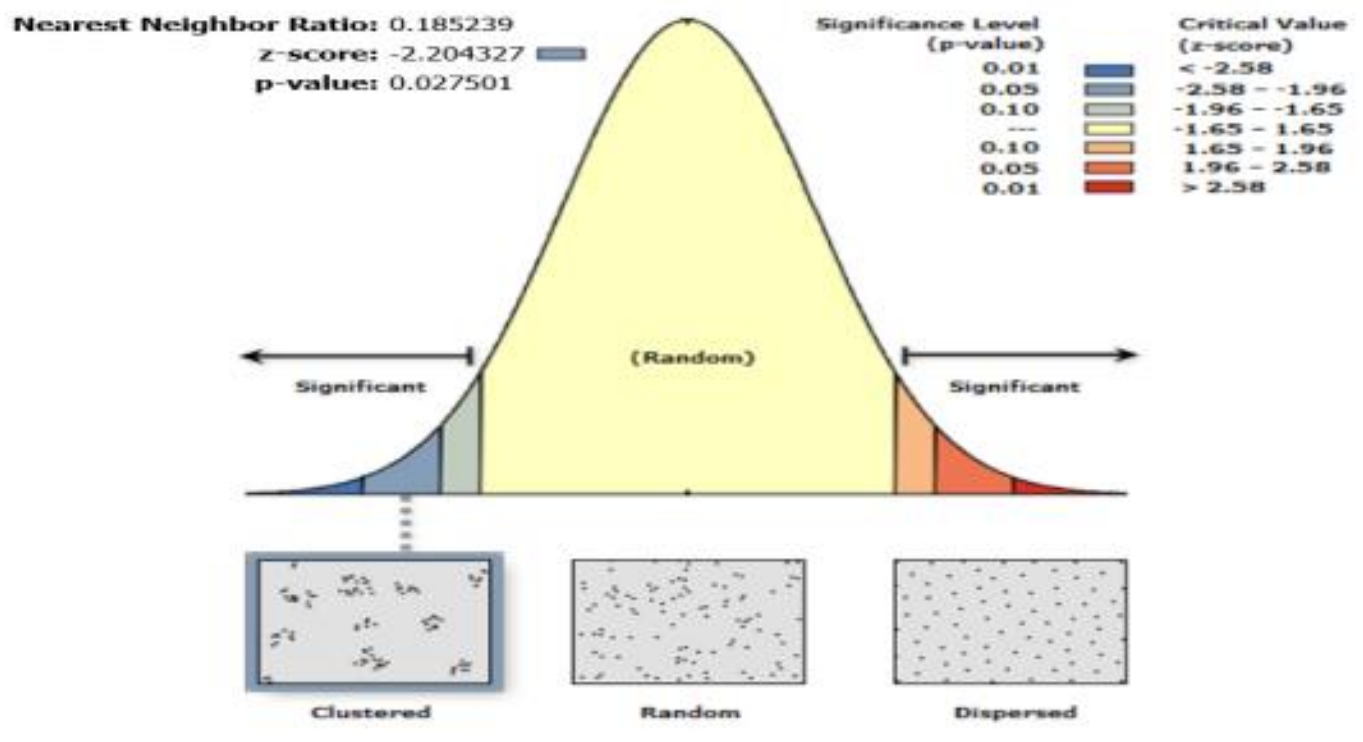

Given the $z$-score of -2.2043268727 , there is a less than $5 \%$ likelihood that this clustered pattern could be the result of random chance.

Figure 6: Analysis for Public Secondary Schools in Herwo Gana 
The Nearest Neighbour Analysis of Public Secondary Schools in Herwo Gana ward revealed an Rn $=0.01$ and critical value of $<-2.58$, with $\mathrm{N}=1$, ward area $=7.4 \mathrm{~km}^{2}$, Nearest Neighbour Ratio: 0.185239 , observed mean distance $=0.0086$, Expected mean Distance $=0.0464$, and the test significance: $p-$ value $0.027501 \mathrm{z}$ - score $=-2.204327$. The result of the analysis showed that all the schools are clustered and the accessibility to secondary schools in the area is relatively even. This can be explained from the fact that the ward is relatively urban.

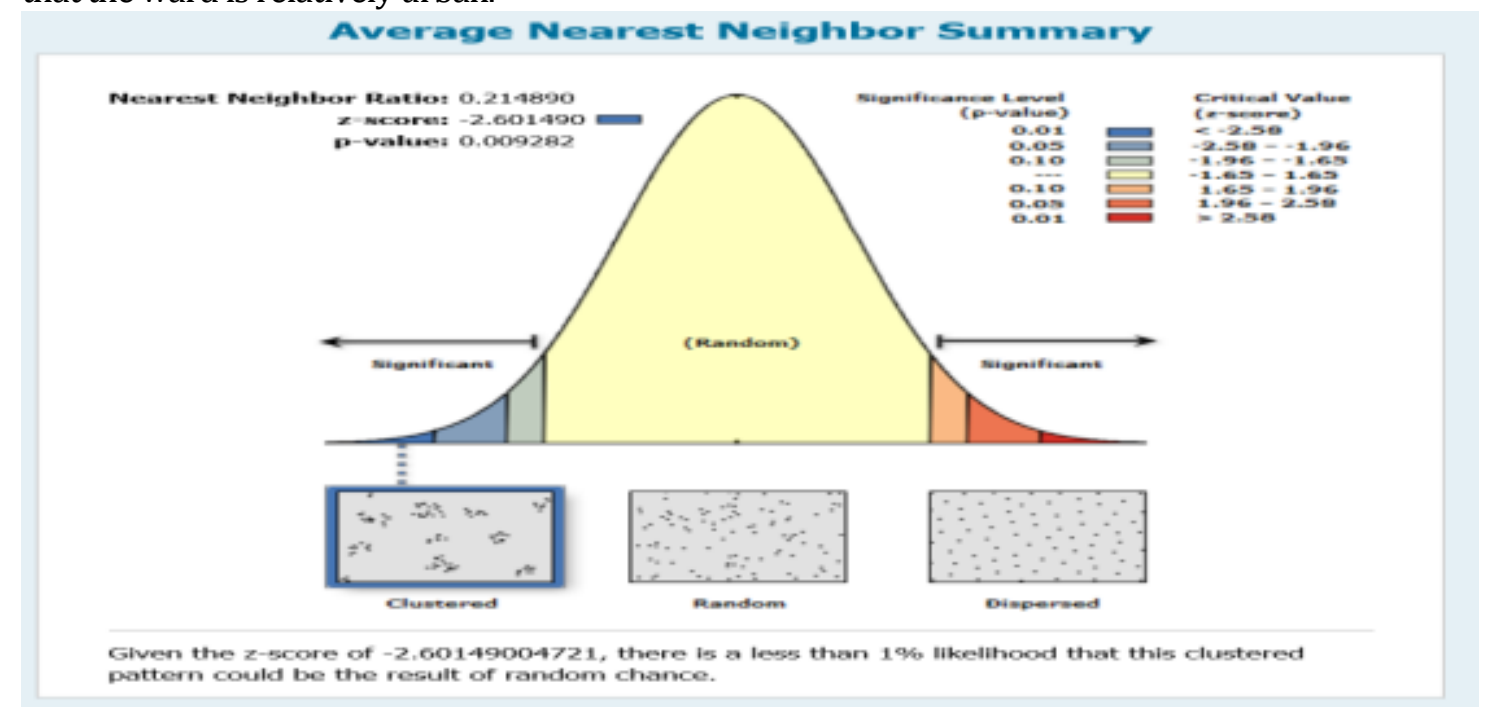

Figure 7: Analysis for Public Secondary Schools in Jekada Fari Ward

The Nearest Neighbour Analysis of Public Secondary Schools in Jekada Fari ward revealed an Rn $=0.01$ and critical value of $<-2.58$, with $\mathrm{N}=2$, ward area $=11.5 \mathrm{~km}^{2}$, Nearest Neighbour Ratio: 0.214890 , observed mean distance $=0.0073$, Expected mean Distance $=0.0340$, and the test significance: $\mathrm{p}-$ value 0.009282 , z- score $=-2.601490$. The result of the analysis showed that all the schools are clustered and there is no equal access to secondary schools in the area.

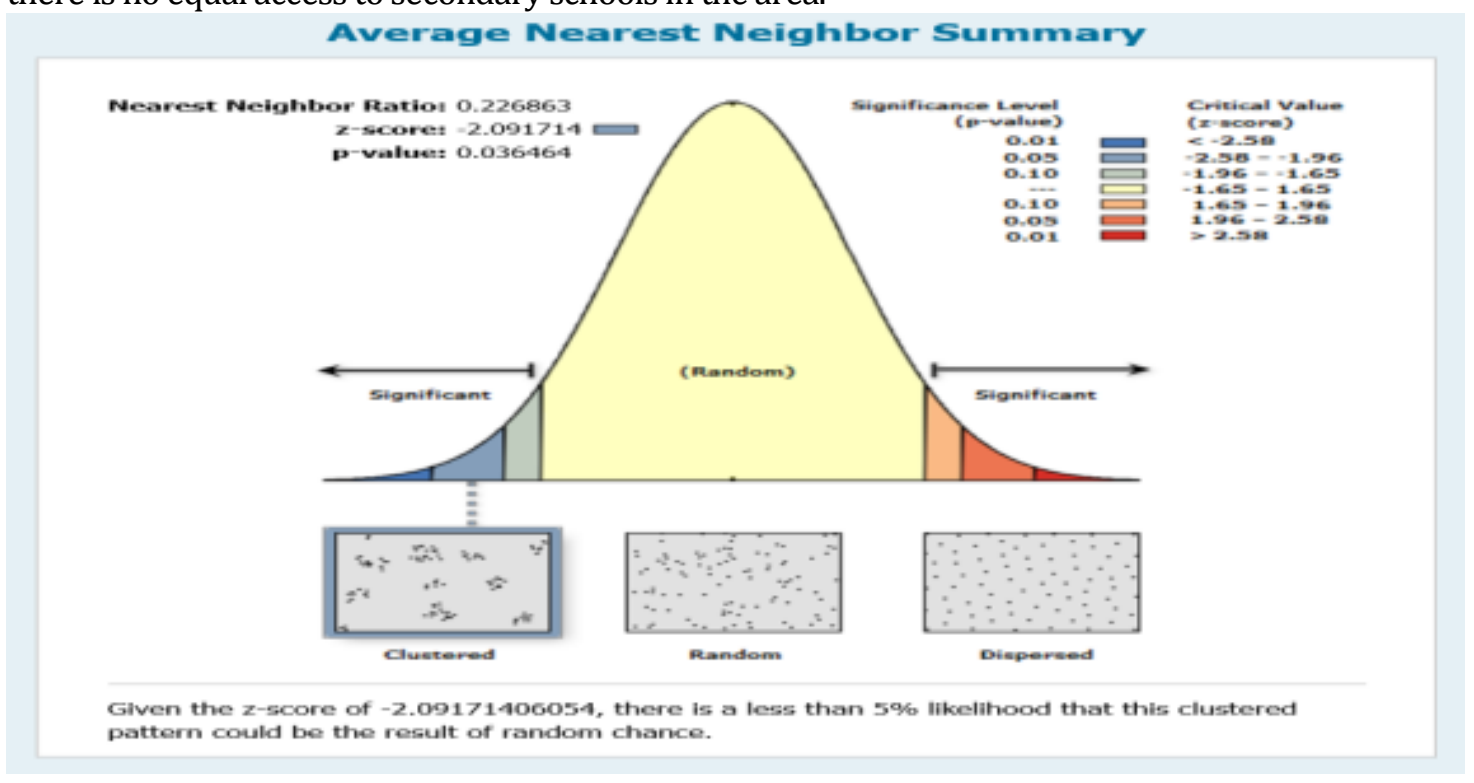

Figure 8: Analysis for Public Secondary Schools in Pantami Ward 
The Nearest Neighbour Analysis of Public Secondary Schools in Pantami ward revealed an Rn 0.01 and critical value of $<-2.58$, with $\mathrm{N}=2$, ward area $=7.6 \mathrm{~km}^{2}$, Nearest Neighbour Ratio: 0.226863 , observed mean distance $=0.0129$, Expected mean Distance $=0.0567$, and the test significance: $\mathrm{p}-$ value 0.036464 , $z$ - score $=-2.091714$. The result of the analysis showed that all the schools are clustered and there is no equal access to secondary schools in the area.

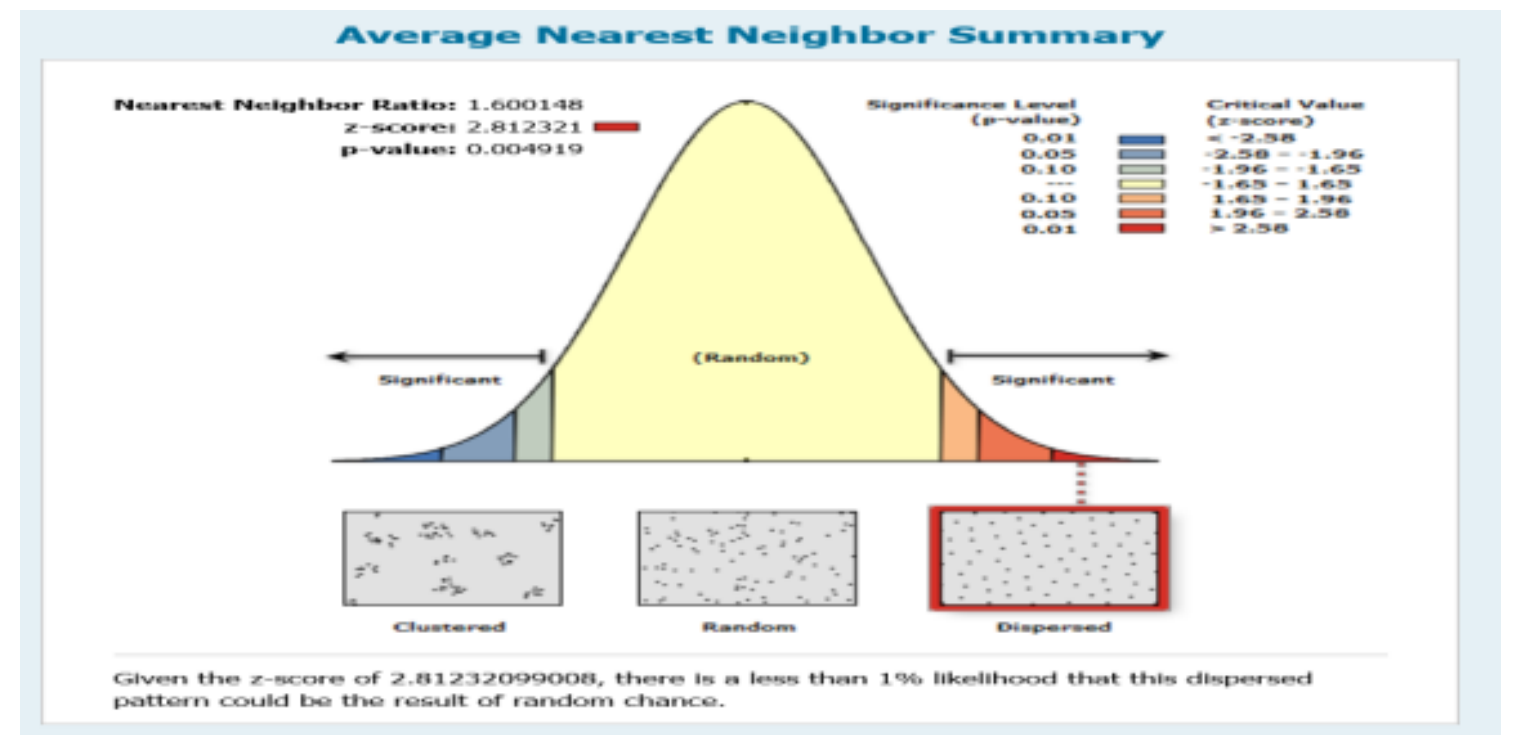

Figure 9: Analysis for Public Secondary Schools in Shamaki ward

The Nearest Neighbour Analysis of Public Secondary Schools in Shamaki revealed an $\mathrm{Rn}=0.01$ and critical value of $>2.58$, with $\mathrm{N}=6$, ward area $=13.7 \mathrm{~km}^{2}$, Nearest Neighbour Ratio: 1.600148 , observed mean distance $=0.0044$, Expected mean Distance $=0.0027$, and the test significance: $\mathrm{p}-$ value 0.004919 $\mathrm{z}=2.812321$. The result of the analysis showed that all the schools are dispersed and there is no even distribution of schools in the area.

\section{CONCLUSION}

The Nearest Neighbour analysis (NNA) for the spatial distribution of secondary schools indicated two categories of patterns of distribution which is dispersed and clustered pattern.

The nearest neighbor index shows clustered pattern for all the wards in the local government area except Bolari East that has dispersed pattern of distribution. The implication of these two patterns means that accessibility is poor in the study area. Students travel than normal to overcome the function of distance.

\section{Recommendation}

The distribution of public secondary schools are not evenly distributed among the ward. Therefore, the need of Gombe State Government are to consider other ward within the study area in other to have equal distribution schools and also to consider the population of base on the distribution of the secondary school in the study area. 


\section{REFERENCE}

Lineberry, (2000). Equality and Urban policy. The Distribution of Municipal public service.

Lu, Y. (2004), Evaluation of Accessibility to primary schools, pp 26 - 31.

Geurs K. T. and Ritsema J.R. (2001). Accessibility measures, review and applications. Bilthoven, Rijksinstituut voor Volksgezondheid en milieu (RIVM).

Lu, Y. (2004). Evaluation of accessibility to primary schools, pp 26 - 31.

World Bank (1996). Priorities and strategies for education report by World Bank development in practice Washington D.C.

Ijaduola K A. (1998). Education in Nigeria: An Historical Perspective. Ijebu-Ode: Odoni (Nig.) Enterprises, pp $68-90$.

Ogunyemi SA, (2014). A geospatial approach to evaluation of accessibility to secondary educational institution in Ogun State, Nigeria. 